\title{
Reasons and Methods to Learn the Management
}

\author{
Hongxin Li \& Mengchun Ding \\ School of Economics and Management, Changchun University of Science and Technology \\ Changchun 130022, China \\ E-mail: 609677303@qq.com
}

\begin{abstract}
Reasons for learning the management include (1) perfecting the knowledge structure, (2) the management is the base of all organizations, (3) one person may be the manager or the managed person, (4) the management is absolutely not simple knowledge, and (5) the learning of the theoretical knowledge of the management can not be replaced by the practice. Methods for learning the management include (1) thinking about the management problems from multiple angles, (2) understanding the management theory from the management practice, (3) learning in cases, (4) having humble and serious attitude, (5) paying attention to the background of the theory, and (6) paying attention to the learning of subsequent theories.
\end{abstract}

Keywords: Management, Learning reasons, Learning methods

The intention of learning the management theory is to apply it in the practice. Good learner of the management theory can not ensure to be excellent manager, and the final success decides individual struggles. However, many people still need to learn the management. Generally speaking, to learn the management theory can make people to form scientific management concepts, promote the change of relative concepts, learn to thinking, open eyes, grasp some basic methods of management, and utilize theories to solve part problems in the life and works. One basic concept to learn the management is to learn being an upright person who will live healthy and work happily. According to the author's understanding about the management, the reasons and methods to learn the management theories are introduced from multiple angles in this article.

\section{Reasons for learning the management}

\subsection{Perfecting the knowledge structure}

Perfect knowledge structure generally includes the society knowledge, the knowledge of the natural sciences, the professional knowledge, the knowledge of scientific leading and management, the knowledge of computer, and the knowledge of age language. The management is a sort of activity existing after the human being occurred. The advancement of the productivity and the deepening of human management practice drive the development of the management ideas, and many systematical management ideas form the management theories which can instruct the management practice. Under the guidance of the management theories, people would further promote the enhancement of the productivity, and promote the updating of management and the further management of the management theories. As the summarization of one aspect in human thoughts, the management relates to all organizations even family and individual, therefore, as one aspects of one person's knowledge structure, the management needs to be grasped and perfected.

\subsection{The management is the base of all organizations}

The management is human activity which exists everywhere and is driven by human thinker. In the past, the enterprises and organizations are more required to solve the problem of the management. In fact, the management problem is the problem faced by all organizations. Whether for profit organizations or whether for nonprofit organizations, whether for big companies or whether for small enterprises, or for all organizations in any countries in the world, the management is very important.

The management is the premise that all organizations operate normally. The function of organization depends on the management which is the main power to harmonize the activities of various parts in the organization and accord with the environment. All organizations need the management, and even one small family needs the management. In addition, with the management, organizations can operate normally, and organizations and managements are phenomena universally existing in the real world.

For all organizations, whether the profit enterprises or the governments or other nonprofit organizations, the efficiency and benefit are the necessary task. As the nonprofit organizations which manage the public products in the society and harmonize the effective operation of the society, to enhance the operation efficiency and benefit of the society, they must have standard system and flow. Nonprofit organizations should not only solve the problems on the layer of the concept, but solve the management problems on the layer of operation. 
The importance of the role of the manger is different between small organization and large organization, but managers engage in basically same works in these two kinds of organization, and the differences only include the degree, the emphasis, the concrete approach and the expended time.

American works on management have been the teaching reference books for many countries in the world, which indicates that whether for the organizations in any countries, the management is very important. At the same, the management theories should not be distinguished for China's and foreign countries', because the competition has universally existed in the whole world.

\subsection{You may manage others or be managed by others}

In one person's life, he may be manager or be managed by others, or at the same time. For people who want to be managers, to learn the management theories can not only help people to acquire basic knowledge, but help them to be effective managers. The early learning of the management theories can help people to acquire quicker benefits in their managerial careers. For those people who don't want to engage in the management, the learning of the management theories can help them to understand seniors' behaviors and the interior operation modes of the organization. The management level of the organization can influence everyone's benefits, and every personnel can propose some advices to promote the works.

\subsection{The management is absolutely not simple general knowledge}

Some one think that the theoretical knowledge of management is just general knowledge, such as laying course and strategy, establishing the organization and institution with good learning, encouragement and control methods, which need not to be learned. But if the management theories are general knowledge, there were not so many failed companies because of bad management. According to the statistics, $80 \%$ problems about the enterprises in China are the problems about management, and $90 \%$ bankrupted enterprises were due toe imperfect management. The decision-making ability can be enhanced and improved by the systematic learning of the management knowledge.

\subsection{The learning of the theoretical knowledge of the management can not be replaced by the practice}

It is not denied that the management knowledge and experiences are mainly from practices, just as the proverbs said, "Knowledge starts with practice", and "Seeing believes". The course of management is highly summarization of relative theoretical knowledge of management with strong science property, theoretical property and practice property. Though the theoretical leaning can not replace the knowledge and skills from the experience, the learning of the management course could offer valuable preparations and compensation for your experiences, because the management theories are the summarization of managers' experiences and lessons, and others' lessons can teach you more to avoid difficulties.

Not all the theoretical researches about management in the teaching materials are away from the management practice, and those real theoretical scholars' researches are all based on real data and materials. If you think their theories would not accord with your concrete practice, that is why you should learn the theories, because even for the person with forty years' working experiences, comparing with human knowledge of management to this day, his knowledge is still very limited, and what those scholars do is to transfer the knowledge you didn't see and think to you.

\section{Methods for learning the management}

Many people think that the management is too "empty" and it is hard to be applied, and the essential cause is that they don't know how to learn the management, and they blindly believe in and follow the management theories like sheep, and the large difference between the reality and theory confuses them. From books to books, they didn't learn the management combining with the practice. And some persons with certain management experiences consider them always right, and can not study in an open mind, and think many theories without values, and they didn't pay attention of the background of the theories, and they lack in subsequently deep learning. Combining with the reasons for learning the management, following aspects are advised to learn the management.

\subsection{Thinking about the management problems from multiple angles}

The management is the summarization of management experiences especially the enterprise management experiences, and part of it has not been perfected and matured. There are many problems in the theory and practice of the management which have not been solved, and learners should not be limited in formers' theoretical limitations but absorb their distillates in theories, and treat formers' theories by developing the useful and discarding the useless, which is the right method to learn the management. 
Therefore, management problems can be considered from many angles, and there is not the master key to solve all problems, and if learners can only follow the opinions of teachers and teaching materials, it is learners' failure to learn the management. Learners should understand the management theories from different angles and boldly propose their own opinions, and should not blindly believe in teachers and scholars' opinions. When studying certain theory or problem, learners should try to refer different opinions such as domestic opinions, foreign opinions, scholars' opinions, experts' opinions, entrepreneurs' opinions, traditional and classical opinions, modern and innovational opinions, and based on various theories, they should compare and analyze the views and applicability of different opinions, and treat problems more comprehensively, and accord with large change of the concrete management problems, and embody the applicable value of theories. If the management equals to the natural science, it should have uniform and strict concept, theory and method, but the art of the management is hard to be understood and grasped, and it is difficult to know how to treat the relationship between the concrete management environment and general management theories. Under that situation, when combining with management practice, learners will make metaphysical mistakes, which will induce the failure of the management practice.

\subsection{Understanding the management theory in the management practice}

The final intention to learn the management theory is to apply it. Because the management theories root in the practice, and serve for the practice, so only by studying, the basic method and opinions of the management can be successfully applied in the analysis and management of practical problems, which can achieve the intention of the learning.

Therefore, the management theories should be really grasped in the practice. If you don't know the practical situations of various organizations, enterprises and companies, you can completely understand them in life. In fact, the management exists everywhere, such as family, class, association, school, even fiction, teleplay and game. If the management thinking is used to think about some quotidian phenomena in life, the effect getting twice the result with half the effort can be achieved.

If you already work, you can search and buy some books about the management in the internet, and research them and survey the management of the organizations around you. If you are a school student, you should actively participate in students' society activities, make the team exercises, and participate in some activities such as seminars after school, and visit more enterprises, and read more relative books. If you have opportunities to communicate with other managers, you can take your grasped management theories as the general outline of the communication, and your communication will be more deep and effective. In the practice or in the internet, if you actively look for the opportunities, you will obtain many communication and learning effects.

\subsection{How to learn by cases}

Case teaching is the normal method that teachers teach the management theories, and cases are the necessary measure to study the management theories.

(1) The selection of cases is the premise. According to the accumulation of knowledge and experiences, the cases can be selected, and sometimes the cases with seeing and hearing will offer higher effects. At present, there are many good management teaching case websites to offer large space for the case selection.

(2) Summarizing cases yourself. Cases come from books and practices and our usual life. Learners should be good at collecting and treating the phenomena happening in the organization management, and problems existing in the practice, and propose the solutions, which is the good method to grasp the management theories.

(3) Three points should be emphasized for the case study. First, learners should know the things which have happened in certain environment. Why it happens by this mode? What are its advantages in the happening things? What are its deficiencies? What can help it to further develop? How this situation happens? Why it happens? Second, what is the next to do? What is the key problem which should be solved? What result can be obtained from the solution of each problem anticipated by the organization? Which prepared scheme should be selected by the organization? Why? Third, for each from of the case cognition, there are quantitative data and subjectively qualitative image. The case research is opening without fixed mode.

(4) Case discussion. If there are opportunities to analyze and discuss cases, it will be the good method to learn cases, such as the successful experiences or failed lessons in famous enterprises, and it is simple to complex, which will continually deepen the discussion. There is not a "right" answer in the case discussion, and its distillate is that every body can realize many unrealized problems in the discussion process to enrich learners' ability to systematically think about the management theories. 


\subsection{Humble and serious attitude}

Learners should not think they really understand the management, and should not be smug and complacent because they have some management experiences, and real leaders need more ideas and foresights. In the world, there is no one enterprise is more large and complex than the government of US, but one appointing president with four years' experiences may be replaced by a youngling without any experience of administrative management, so you need considering out of the cage of experience. Many entrepreneurs can not really know what these basic concepts such as strategy and core competition are, and don't know how to implement the human resource management, and how to make leaders more charming, how to evaluate employees, how to encourage employees, how to communicate and how to control management.

\subsection{Paying attention to the background of theories}

Many management theories have not only concrete application conditions, but also their own hypotheses. Without these cognitions, many learners will feel that much theoretical knowledge about management are not practical, and feel they are "empty" without actual application values. And the values of these theories can not be denied. For example, many learners think that Marslo's demand level theory is not useless, and only if learners associate with their own work practice, and avoid the nihilism and blindly following, they can know its real values, which is the right learning method.

In addition, the knowledge of management has its own limitation which roots in the background of the subject knowledge, and the conflict between the western theory migration and the eastern situation will also occur, and the key is that whether the learner can learn the method behind the knowledge, which is the essence of the management.

\subsection{Paying attention to the learning of subsequent theories}

After studying the basic knowledge of management, learners should study some very practical knowledge combining with their own works as follows.

(1) Read some books about "how to be a good leader" and "how to be a good employee", and gradually possess the quality and habits of good leaders and good employees.

(2) Study and understand the functions of the training and the employee career development planning for employees, and develop the training for employees, and transfer relative knowledge to employees, and make employees' career development planning well.

(3) Study and understand the function of the control system in the management, and discover and perfect the deficiencies of the control system of the organization.

(4) Study and understand the knowledge and function of the organization culture, and make clear the relationship between the organization system and the organization culture, and learn to the method building the organization system and the organization culture, and study and know the relationship between the leader's quality and habit with the enterprise culture.

(5) Taste the function of the performance appraisal in the management in the learning and working, and establish and utilize an effective performance appraisal system.

There are thousands of reasons and methods for learn the management. Above aspects are only the author's experiences leaving much to be desired, which are advised to communicate with relative researchers.

\section{References}

Pan, Jianlin. (2007). My Opinions on the Teaching of Management. Website of Selected Course of Yiwu Industrial \& Commercial College: Base of Management. July of 2007.

Stephen. P. Robbins. (1997). Management (fourth edition). Beijing: China Renmin University Press.

Tan, Haiou. (2008). Exploring of the Teaching Method of Management. College Teaching Research. No.5.

Thomas Bateman \& Skot Snell. (2004). Management (fourth edition). Beijing: Peking University Press.

$\mathrm{Xu}$, Deyin. (2006). A Business College Professor's Teaching Commandments of the Management Course. 21st Century Business Herald. March 6, 2006. Edition 27.

Zhang, Kai \& Sun, Hui. (2009). Study on the Teaching Mode of Management: Taking the Talent Cultivation of Ji'nan University as the Target. Website of Selected Course of Management School of Ji'nan University. 